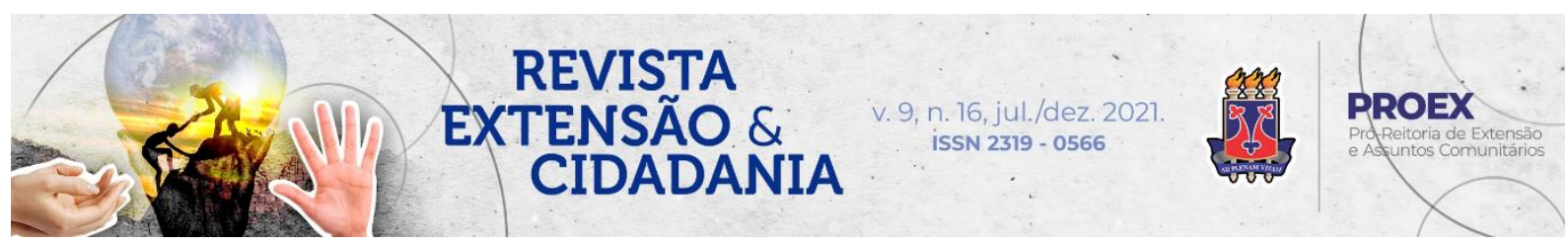

DOI: $10.22481 /$ recuesb.v9i16.9572

\title{
DIREITO À POESIA - UMA OFICINA LITERÁRIA EPISTOLAR DURANTE A PANDEMIA DE COVID-19
}

\section{RIGHT TO POETRY - AN EPISTOLARY LITERARY WORKSHOP DURING THE COVID-19 PANDEMIC}

\section{DERECHO A LA POESÍA - UN TALLER LITERARIO EPISTOLAR DURANTE LA PANDEMIA DEL COVID-19}

\author{
Cristiane Checchia ${ }^{1}$ \\ Mario René Rodríguez Torres ${ }^{2}$ \\ Layra Fabian Borba Rodrigues ${ }^{3}$ \\ Jhenifer Rodrigues de Almeida ${ }^{4}$ \\ Angélica Moreno Usaquin ${ }^{5}$ \\ Anderson Alves dos Santos ${ }^{6}$
}

Resumo: O Direito à Poesia é um projeto de extensão desenvolvido por docentes e estudantes da Universidade Federal da Integração Latino-Americana (UNILA), na cidade de Foz do Iguaçu-PR, desde o ano de 2015. O projeto consiste na realização de rodas de leitura e de oficinas de escrita com pessoas em privação de liberdade em duas unidades penitenciárias da cidade, a PEF-II (masculina) e a PFF-UP (feminina). Devido ao contexto da pandemia da Covid-19, no ano de 2020, o projeto precisou ser reconfigurado para que pudesse continuar acontecendo mesmo sem a possibilidade de encontros presenciais entre as/os participantes, o que foi possível por meio da troca de cartas. O presente trabalho apresenta justamente essa

\footnotetext{
1 Doutora em Letras/Literatura. Docente da área de Letras, na Universidade Federal da Integração Latinoamericana (UNILA), Foz do Iguaçu, Paraná, Brasil. Orcid: https://orcid.org/0000-0002-3039-0463 E-mail: crischecchia@gmail.com

2 Doutor em Ciência da Literatura. Docente da área de Letras, na Universidade Federal da Integração Latinoamericana (UNILA), Foz do Iguaçu, Paraná, Brasil. Orcid: https://orcid.org/0000-0002-5733-9481 E-mail: mario.torres@unila.edu.br

${ }^{3}$ Estudante de Ciência Política e Sociologia, pela Universidade Federal da Integração Latino-americana (UNILA), Foz do Iguaçu, Paraná, Brasil. Orcid: https://orcid.org/0000-0001-5422-0197 E-mail: layrafab@gmail.com

${ }^{4}$ Estudante de Ciência Política e Sociologia, pela Universidade Federal da Integração Latino-americana (UNILA), Foz do Iguaçu, Paraná, Brasil. Orcid: https://orcid.org/0000-0003-0270-598X E-mail: jheyrodrigues.a@gmail.com

${ }^{5}$ Estudante de Letras, Artes e Mediação Cultural, pela Universidade Federal da Integração Latino-americana (UNILA), Foz do Iguaçu, Paraná, Brasil. Orcid: https://orcid.org/0000-0003-2296-3804 E-mail: usaquin.angelica@gmail.com

${ }^{6}$ Estudante de Filosofia, pela Universidade Federal da Integração Latino-americana (UNILA), Foz do Iguaçu, Paraná, Brasil. Orcid: https://orcid.org/0000-0002-2574-3623 E-mail: aad.santos.2016@aluno.unila.edu.br
} 
experiência e os desafios encontrados para o desenvolvimento destas oficinas na modalidade epistolar. As produções literárias resultantes desse processo formaram uma minibiblioteca de zines reunidos em caixinhas que podem circular pelo presídio. Para nós, essa produção é de suma importância por se relacionar diretamente com o objetivo principal do Direito à poesia: criar condições para que a palavra poética e as vozes singulares de distintos lugares possam romper seus respectivos muros e encontrar-se em espaços e meios diversos de circulação.

Palavras-chave: Mediação de Leitura. Oficinas literárias. Prisão. Extensão Universitária. Cartas.

Abstract: The Direito à Poesia (Right to Poetry) is a university extension project developed by lecturers and students of the Federal University of Latin American Integration (UNILA), in the city of Foz do Iguaçu-PR, since 2015. The project is developed by implementing reading groups and writing workshops with people in prison in two penitentiaries in the city, the PEF-II (male) and PFF-UP (female). Due to the Covid-19 pandemic context, in 2020, the project had to be reconfigured to continue happening even without the possibility of face-to-face meetings between the participants, which was possible through the exchange of letters. The present work precisely presents this experience and the challenges encountered in developing these workshops in the epistolary modality. The literary productions resulting from this process formed a mini-library of zines collected in little boxes that can circulate around the prison. For us, this project is of utmost importance because it is directly related to the main objective of the Right to Poetry: to create conditions for the poetic word and the singular voices of different places to break through their respective walls and find themselves in different spaces and medium of circulation.

Keywords: Reading Mediation. Literary Workshops. Prison. University Extension. Letters.

Resumen: Derecho a la Poesía es un proyecto de extensión desarrollado por profesores y estudiantes de la Universidad Federal de la Integración Latinoamericana (UNILA), en la ciudad de Foz do Iguaçu-PR, desde 2015. El proyecto consiste en la realización de círculos de lectura y talleres de escritura con personas privadas de la libertad en dos unidades penitenciarias de la ciudad, la PEF-II (masculina) y la PFF-UP (femenina). Debido al contexto de la pandemia de Covid-19, en el año 2020 fue necesario reconfigurar el proyecto para que pudiera seguir realizándose incluso sin la posibilidad de encuentros presenciales entre los participantes, lo que fue posible a través del intercambio de cartas. Este trabajo presenta precisamente esa experiencia y los retos encontrados para desarrollar los talleres en la modalidad epistolar. Las producciones literarias resultantes del proceso formaron una minibiblioteca de fanzines recogidos en cajitas que pueden circular por la prisión. Para nosotros, esta producción es de suma importancia porque está directamente relacionada con el objetivo principal de Derecho a la Poesía: crear las condiciones para que la palabra poética y las voces singulares de diferentes lugares puedan romper sus respectivos muros y encontrarse en diferentes espacios y medios de circulación.

Palabras clave: Mediación de la lectura. Talleres literarios. Prisión. Extensión Universitaria. Cartas.

Revista Extensão \& Cidadania, v. 9, n. 16, p. 212-231, jul./dez. 2021.

ISSN 2319-0566 DOI: 10.22481/recuesb.v9i16.9572 


\section{Introdução}

Escrever cartas é coisa de outro tempo, como as antenas de televisão que Rômulo fabrica com tampas de panelas para as rádios e televisões de seus companheiros de cela, na ala de idosos de uma galeria da Penitenciária Estadual de Foz do Iguaçu (PEF-II). Estar privado de liberdade é, de certa forma, ser deixado para trás e, portanto, ser obrigado a fazer coisas que, se supõe, ninguém mais faz. Fabricar antenas e escrever cartas no presídio são atividades que se fazem devido às limitações, à exclusão e à precariedade que se enfrenta, mas também são formas criativas e vitais de habitar o contratempo, a carta impõe outro ritmo, um ritmo mais lento, obriga a pausas. Parar, se deter, pode gerar dificuldades, ansiedades e desconfortos, mas é também uma brecha no acelerado tempo atual e, por isso, a possibilidade de outro tempo. Nesse sentido, a carta pode ser intempestiva (NIETZSCHE 2003) ou contemporânea (AGAMBEN 2009).

Viver em outro ritmo, escrever cartas, quando em 2020 tudo parava, devido ao confinamento pela pandemia da Covid-19, foram as cartas as que permitiram que déssemos continuidade às nossas atividades na penitenciária masculina PEF-II. Nosso objetivo neste texto é justamente compartilhar como se deu esta experiência e algumas das reflexões que nos acompanharam ao longo do processo. O trabalho aqui exposto é fruto do projeto de extensão universitária Direito à Poesia, desenvolvido por docentes e estudantes da Universidade Federal da Integração Latino-Americana (UNILA), localizada em Foz do Iguaçu, região da tríplice fronteira entre Brasil, Paraguai e Argentina.

O texto apresenta brevemente alguns dos pressupostos e o contexto do desenvolvimento do projeto em 2020 para, em seguida, expor tematicamente questões que emergiram dessa experiência epistolar: a velhice na condição de encarceramento; as questões de gênero, a literatura e as prisões; o choro masculino; a escrita e as artes enquanto exercício de liberdade no contexto prisional e de pandemia. Por fim, expomos o resultado editorial das oficinas deste ano: uma antologia de textos reunidos em uma minibiblioteca perambulante.

Para manter a diversidade das vozes que compõem o grupo, cujos/as componentes têm formações em áreas bastante variadas (literatura, sociologia, serviço social, filosofia, mediação cultural), decidimos que cada um dos/das autoras, docentes e discentes escrevesse uma parte do trabalho, sem pretender homogeneizar completamente o tom geral do texto. Lamentavelmente, as vozes das pessoas privadas de liberdade só estão presentes de forma indireta, a partir de

Revista Extensão \& Cidadania, v. 9, n. 16, p. 212-231, jul./dez. 2021. 
citações de suas cartas, que elas nos autorizaram expressamente a publicar, só mencionaremos seus primeiros nomes, a fim de preservarmos suas identidades.

\section{Metodologia}

O Direito à poesia começou a ser desenvolvido no ano de 2015 e, desde então, organizase fundamentalmente a partir de dois núcleos de trabalho articulados: um deles constitui-se da formação dos estudantes e docentes em um grupo de estudos, no qual discutimos textos de fundamentação teórica e crítica sobre a questão carcerária e sobre a mediação de leitura e escritura em contextos adversos; o outro núcleo configura-se da prática da mediação de leitura e escritura dentro de ambientes prisionais, ou seja, da realização de oficinas literárias nas prisões de Foz do Iguaçu, a Penitenciária Estadual II (PEF-II) e a Penitenciária Feminina de Foz do Iguaçu (PFF-UP).

Tais oficinas literárias são organizadas a partir de diversos momentos que vão sendo alternados na dinâmica dos encontros: a leitura em voz alta; a conversa livre mobilizada pelos textos; a proposição de exercícios de escritura a partir da leitura; o compartilhamento dos textos produzidos por cada participante e o diálogo a partir dessa produção.

A pandemia da Covid-19 e o isolamento obrigatório dela decorrente implicaram no cancelamento das oficinas literárias presenciais, levando-nos, na primeira metade de 2020, a fortalecer o grupo de estudos por meio de leituras e de encontros on-line. Com isso, buscamos aprofundar nossa compreensão sobre os processos históricos nos quais surgiu o modelo de prisão e o sistema penal contemporâneo, bem como as adaptações que esse sistema sofreu para chegar no momento atual.

Depois de junho, conseguimos formalizar outra forma de executar o projeto na PEF-II, mediante troca de cartas literárias. Em 2020, as cartas foram a ferramenta que nos permitiu sair de nosso confinamento e, em um sentido mais amplo, de nossos espaços restritos, incluindo o universitário, e acessar o espaço outro do cárcere. Por meio de reuniões on-line e de documentos organizados em um arquivo compartilhado, produzimos a primeira carta a ser enviada a um grupo de 23 participantes no interior da PEF-II, que se interessou pela proposta. Nesta primeira carta, nós nos apresentamos e expusemos o contexto institucional ao qual estamos vinculados (a universidade pública, o projeto de extensão universitária). Além disso, reunimos alguns textos que julgamos pertinentes para iniciar o diálogo, incorporando escritos que resultaram de

Revista Extensão \& Cidadania, v. 9, n. 16, p. 212-231, jul./dez. 2021. 
edições anteriores de nossas oficinas presenciais na própria PEF-II, ou de oficinas realizadas por grupos semelhantes ao nosso em outras penitenciárias. Procuramos mobilizar algumas perguntas bem abertas que os estimulassem a escrever: $\mathrm{O}$ que você achou dos textos? Ao seu ver, de que trata cada um deles? Algum dos textos fez você lembrar de algo que tenha lido, escutado, visto ou vivido? Achou difícil a leitura de algum dos textos? Há alguma palavra neles cujo significado você não conheça? Etc.

Nossa maior preocupação era recriar, na medida do possível, a mesma horizontalidade e um "espaço de escuta" similar ao que buscamos desenvolver nas oficinas presenciais. Os desafios eram grandes, porque, conforme Bajour (2012, p.17-19), na dinâmica de uma roda de leitura presencial, o lido se amalgama às vozes pronunciadas, às interações quase simultâneas entre as falas, aos olhares trocados, às posições de corpo, que produzem também significações juntamente com os textos. Nada disso estaria ao nosso alcance na oficina epistolar, mas desde o início apostamos na viabilidade de criar por meio das cartas um espaço de trocas em que nos mostraríamos verdadeiramente disponíveis para "ouvir" o que teriam a nos dizer, tendo os textos literários como um lugar de "encontro".

Acreditamos ser importante uma descrição mais detalhada de todo o processo, tal como ocorreu na prática. Todo o material foi impresso e levado à PEF-II, onde a pedagoga Maria Luiza da Silva recebeu os textos e os distribuiu aos participantes em privação de liberdade, respeitando as medidas de segurança sanitária para a entrega dos materiais. As respostas foram trabalhadas pelos participantes em comentários diretamente no papel, que íamos buscar na semana seguinte. A partir do retorno, líamos e conversávamos para pensarmos as respostas e a seleção dos textos que comporiam a entrega seguinte. Este trabalho de troca de correspondências foi desenvolvido ao longo de todo o segundo semestre de 2020, e cabe ressaltar aqui, o papel fundamental da pedagoga e de alguns agentes que viabilizaram toda a logística desta troca de materiais.

A escolha dos temas para os exercícios de escrita tiveram como base não apenas nossa experiência acumulada a partir das oficinas presenciais, mas também as experiências de outros projetos muito inspiradores de oficinas literárias e artísticas em prisões, os quais tivemos a oportunidade de conhecer por meio de publicações, e também a partir de um evento realizado na UNILA, em 2019, o $1^{o}$ Encontro Internacional sobre poesia e artes em prisões - da perspectiva do anti-aprisionamento ${ }^{1}$. Alguns dos temas trabalhados nas primeiras entregas, para darmos alguns exemplos, foram: o autorretrato poético; a descrição de seu dia tentando

Revista Extensão \& Cidadania, v. 9, n. 16, p. 212-231, jul./dez. 2021. 
fazer o uso da terceira pessoa no relato; a pergunta "por que escrever?". A partir destes primeiros exercícios e das primeiras respostas que nos enviaram, outros temas foram mobilizados por eles.

Alguns temas surgiram de forma recorrente, como a questão da velhice, outros temas controversos explorados nas escritas provocaram diversas reflexões no grupo. Tentamos trazer nesse trabalho alguns desses temas, realizando discussões sobre seus possíveis significados e as contradições que revelam. Em vista disso, a seguir, discutimos algumas dessas questões, as quais foram agrupadas nos seguintes grupos temáticos: velhice na prisão; questões de gênero, literatura e prisões; o choro masculino; a escrita enquanto exercício de liberdade; e, por último, uma reflexão sobre o cárcere em tempos da pandemia.

\section{Velhice na prisão}

Quando pensamos em pessoas privadas de liberdade, a imagem que nos vem não costuma ser a de pessoas mais velhas. Segundo dados do Departamento Penitenciário Nacional, em 2019, havia 748.009 pessoas aprisionadas, das quais $95,06 \%$ eram homens e destes, $44,79 \%$ tinham idade entre 18 e 29 anos (BRASIL, 2019). Apesar disso, o grupo com o qual interagimos na PEF II durante a troca de cartas era composto por homens entre 30 e 73 anos de idade, sendo que a maioria estava acima dos 50 anos. Assim, desde o início, uma questão surgiu para o grupo: como é estar privado de liberdade sendo idoso? Cabe mencionar que foi na troca de cartas que ficamos sabendo que os participantes eram na sua maioria pessoas mais velhas, de modo que a galeria foi apelidada de "galeria da terceira idade". A questão da idade apareceu tanto como um dado que eles agregaram junto de seus nomes, como também um tópico que tematizaram mais longamente em suas cartas.

Nessa troca de cartas, poderíamos chamar a atenção para quatro momentos que os participantes se relacionaram mais diretamente ao tema da idade. São eles: o texto Velhice na prisão, de Eliseu; dois relatos sobre o trabalho de cuidado de idosos, feitos por Telêmaco e Rômulo; e outros dois textos, um denominado $O$ que sinto na prisão e outro sem título, escrito por Oldenon. No primeiro, lemos sobre a determinação em superar a autodepreciação, as angústias de cada dia e as memórias dolorosas do passado. Esse texto transmite uma sensação de apatia, que se mescla à luta pela sobrevivência de cada dia.

Revista Extensão \& Cidadania, v. 9, n. 16, p. 212-231, jul./dez. 2021 
Telêmaco, por sua vez, conta em seu relato que ele cuida dos idosos com maiores dificuldades, de maneira que frequentemente precisa acolher novas pessoas a serem atendidas e, por conta disso, deve escolher quem deixará de receber esses cuidados para abrir espaços na cela. Esta é uma escolha que o aflige. No texto de Rômulo, há o relato sobre a felicidade que sentiu quando a administração da penitenciária transferiu os idosos cuidados por ele e os deficientes para uma galeria mais próxima da enfermaria e dos médicos, facilitando assim o atendimento das pessoas com problemas de saúde.

Quanto aos escritos de Oldenon, o autor fala sobre a velhice a partir de dois processos: o de voltar a ser criança e o de amar. No primeiro caso, explica que pelo trabalho continuado e intenso desde criança, não teve infância ou adolescência, além de que sempre precisou trabalhar para ter suas coisas. Isso só foi mudar no cárcere, onde ele passou a depender dos outros, não podendo trabalhar ou saber a origem das coisas que recebia, tampouco buscar o tratamento necessário para seus problemas de saúde. Tais situações lhe pareceram como o retorno a uma infância (não vivida), como se voltasse, ou melhor, aprendesse a ser criança. Em nossa resposta à sua carta, procuramos estabelecer com ele uma interlocução sobre o que havia nos dito e o texto Manicômios, prisões e conventos, de Erving Goffman (1974). Tal autor afirma que determinadas instituições, como a prisão, devolvem as pessoas à condição de infante, porque tiram delas a autonomia e as tornam completamente dependentes de outras. A palavra infante é de origem latina e, etimologicamente, significa "aquele que não fala". Nesse sentido, fizemos a Oldenon a seguinte provocação: poderíamos pensar que escrever é um caminho para sair dessa condição de infante, isto é, de não falante, e, portanto, de recuperar algo da autonomia perdida? Como resposta a essa incitação, na entrega da carta seguinte, Oldenon nos escreveu um texto sobre o amor. Neste, afirma que apesar de lhe chamarem de velho, ele ainda é jovem, jovem no coração e capaz de amar e ser amado. Afirmando amar e ser amado, Oldenon se insurge contra os constrangimentos da prisão, ou seja, contra a perda da sua autonomia e das suas possibilidades de afeto e amor.

Existem diferentes realidades no cárcere e, sendo assim, distintas formas de se vivenciar a velhice na prisão. Para alguns, a velhice na prisão pode significar memórias dolorosas, apatia, luta por aceitação e sobrevivência. Para outros, ela é aproximada à infância, ao ser associada à dependência e à incapacidade de trabalhar e de se fazer escolhas, e que demandaria um reaprendizado da capacidade de dar e receber amor. Para outros ainda, a velhice na prisão implica em escolhas de Sofia todos os dias (de quem poderei cuidar, hoje?). De toda forma,

Revista Extensão \& Cidadania, v. 9, n. 16, p. 212-231, jul./dez. 2021. 
essas realidades não se circunscrevem aos estigmas que as permeiam, pois são muito mais ricas, cheias de nuances e cores do que podemos imaginar. Há lágrimas, apatia e raiva, contudo, existe também cuidado, amor e jovialidade, a velhice na prisão é multifacetada.

\section{Questões de gênero, literatura e prisões}

Um dos dilemas que muito frequentemente atravessa o desenvolvimento de nosso projeto é a atenção permanente que devemos ter para não cedermos a algumas armadilhas: uma delas seria a de nos colocarmos no lugar de quem julga; a outra seria a de nos colocarmos em uma atitude pastoral, tão presente em trabalhos de viés religioso, mas não apenas com a população prisional.

Quando tais questões emergem, somos convidados a pensar novamente sobre os pressupostos políticos que embasam nossa atuação, os quais expusemos em outro artigo (RODRÍGUEZ TORRES; CHECCHIA, 2020), mas que em poucas palavras poderíamos resumir como se posicionar contra toda forma de censura, fechamento ou clausura antidemocrática. Tal postura, inevitavelmente, nos coloca ante desafios éticos e isso aconteceu também ao longo de nossa troca de cartas.

Um de nossos pontos de partida no projeto é a ideia de que a literatura abre efetivamente uma liberdade para a expressão de temas, gestos, palavras que muitas vezes estão interditados em outros regimes discursivos, como no discurso religioso fundamentalista ou no discurso burocrático, ou jurídico ou acadêmico mais convencional etc. A criação de personagens, a exploração de distintos pontos de vista, a construção de situações apenas imaginárias, a descrição de lugares e paisagens inexistentes, o jogo de ritmos e sons são recursos que permitem que se diga tudo, justamente porque não se espera que o escrito tenha necessariamente um lastro em uma verdade referencial fora do texto. Daí que Jacques Derrida (1995, p. 47), autor fundamental para nossa compreensão da literatura, afirme que ela "liga [...] seu destino a uma determinada não-censura, ao espaço da liberdade democrática (liberdade de imprensa, liberdade de opinião etc.)".

Por permitir, em princípio, dizer tudo (e nada), a literatura é um espaço privilegiado para os questionamentos, o abandono das certezas e abertura de horizontes. Contudo, é preciso reconhecer, como faz o próprio Derrida, que desde sempre existiram mecanismos para controlar, neutralizada e, inclusive, instrumentalizar com fins conservadores tal espaço (DERRIDA; ROUDINESCO 2004). Não é possível aqui nos aprofundarmos na longa discussão

Revista Extensão \& Cidadania, v. 9, n. 16, p. 212-231, jul./dez. 2021. 
sobre o tema, limitamo-nos a apontar que nada impede que a literatura possa servir como veículo, com ou sem má-fé, para os discursos mais antidemocráticos, excludentes e violentos. Como responder a esses discursos sem trair a promessa de liberdade de expressão atrelada à literatura? Seguramente não há uma única resposta, devendo ela ser diferente a depender de cada caso.

Nas nossas oficinas, deparamos com um texto que nos desafiou nesse sentido, um participante do projeto escreveu, em uma de suas cartas, um poema narrativo a partir da paródia de uma canção na qual o protagonista narrador sente-se vingado e justiçado pelo assassinato violento da mulher que o traiu. Como lidar com um texto como esse? Trata-se de um texto ficcional, mas que gera uma zona de ambiguidades difícil de lidar. Como não ceder ao julgamento e, ao mesmo tempo, como não deixar passar algo que parece legitimar o ciclo de violência de gênero que buscamos combater socialmente? Como manter o diálogo para que este texto possa de fato abrir caminhos à reflexão?

Primeiramente, apesar de um desconcerto inicial que não conseguimos evitar, pareceunos significativo que o participante tenha sentido abertura para expor um texto que não seria assimilável quando quem escreve tenta apenas suprir a expectativa de um discurso de redenção já pré-acabado. Havia ali uma provocação, talvez, mas também a expectativa de um retorno, nos pareceu. Nossa ideia foi a de tentar manter a disposição ao diálogo, o que não aconteceria se devolvêssemos apenas uma condenação veemente do personagem criado. Procuramos discutir a partir da própria ficção: lembrando que muita literatura foi produzida a partir do tema da traição, conversando a partir de Madame Bovary e dessas personagens que não se encaixam às regras de seu tempo, pensando qual é o papel que é esperado socialmente das mulheres e lembrando que também há um fardo pesado de expectativas sociais em relação aos homens. Perguntamos ainda o quanto custa aos homens manter esse papel que restringe sua possibilidade de expressar sentimentos, fraquezas e frustrações. O diálogo continuou e efetivamente não temos como saber que efeito teve sobre nosso interlocutor. Sabemos apenas que apesar do provável desconforto que nossas questões colocavam, ele seguiu com a correspondência até o final do projeto.

Angela Davis (2018) nos lembra bem que imaginar uma sociedade sem prisões implica em refletir sobre múltiplos problemas, extremamente complexos, e que não há uma solução que dê conta de todos eles. Uma das tarefas seria enfrentar os efeitos decorrentes do machismo, que naturaliza a violência de gênero e que anualmente leva à morte de milhares de mulheres e à

Revista Extensão \& Cidadania, v. 9, n. 16, p. 212-231, jul./dez. 2021. 
continuidade de um ciclo de violências que não se extingue nas prisões, muito pelo contrário. Sabemos que as prisões, cujos códigos internos muitas vezes legitimam os chamados "crimes de honra", são lugares que enrijecem ainda mais as estruturas patriarcais tão arraigadas socialmente. Pensar em um mundo sem prisões, menos violento, pressupõe também confiar na abertura de mais canais de diálogo para discutir o tema das masculinidades: a literatura pode ser um lugar bastante privilegiado de uma desorganização salutar das cristalizações dos papéis de gênero que tanto sofrimento causam.

\section{O choro masculino}

$\mathrm{Na}$ esteira das reflexões despertadas sobre gênero, masculinidades e machismos, seguimos agora para uma discussão que envolveu a maioria, senão todos, os participantes do projeto. Numa das entregas, João Carlos escreveu um relato em que o personagem narrador, um idoso, é interpelado com violência por um jovem colega de prisão que diz para ele: "veio, você sofre". O idoso nega, mas o jovem não aceita contestação e repete a sentença. Na nostalgia que envolve o descanso pós-almoço, o narrador angustia-se em torno da afirmação incontestável. Nesse momento, vem-lhe à mente a voz de seu pai dizendo que "homem que é homem não chora", sendo esse, segundo o narrador, também o mantra da prisão, "sujeito homem não chora". No fim, o que resta para ele é se virar para o lado e se fazer "moleque".

Assim, movidos pela intensidade desse texto e de todas as questões que o envolvem, na entrega que seguiu, decidimos abordar o tema do "choro masculino". Para isso, colocamos três referências: a música Jesus Chorou, do grupo de RAP Racionais MC's; o texto Instruções para chorar, de Júlio Cortázar; e o conto Lágrimas de Crocodilo, de Felisberto Hernández. A partir dessas leituras, fizemos duas perguntas: qual texto chamou mais sua atenção e por quê? Já presenciaram uma cena de um homem chorando? Esta última pergunta tinha a intenção de os estimular a (re)criar a cena com total liberdade literária. Era um convite para que os participantes compartilhassem seus pensamentos e reflexões em torno do assunto, mas não fazíamos ideia de como reagiriam.

O texto que mais reações provocou foi "Jesus chorou", pois ela toca em um pilar muito presente no meio carcerário, que é a religião. Alguns participantes apontaram ainda o capítulo e versículo da bíblia onde o choro de Jesus pode ser encontrado, o que demonstra interesse e uma reflexão prévia sobre o assunto. Para José Valdir, ler sobre isso lhe traz uma sensação

Revista Extensão \& Cidadania, v. 9, n. 16, p. 212-231, jul./dez. 2021. 
inexplicável, pois entende que as lágrimas nos olhos do criador são por nossa causa, pela rebeldia das pessoas que não seguem seus ensinamentos. Assim, ele ressalta: "e creio que Jesus ainda chora ao ver tantos corações endurecidos praticando o mal e não se arrependendo". Para Alinor, por outro lado, "o choro é de todas as mulheres e homens. São fatos reais. São de tristezas que vem de emoções que atingem o coração".

Durante a troca de cartas, uma coisa que se fez bastante evidente foi a importância que a religião assume na conduta e vida dos privados de liberdade. Em grande parte dos textos, sejam os literários, os de memórias ou os de elogio ao projeto, os agradecimentos e louvores a Deus estão presentes. A religião parece assumir um papel de grande destaque em suas vidas, seja por trazer esperança de um futuro distinto como a reaproximação da família, seja pela possibilidade de redenção de um passado do qual não se orgulham ou mesmo pela mudança de crenças, valores e propósitos que traz para seu cotidiano. Falamos sobre isso, para que se entenda melhor a importância de encontrarem na bíblia uma passagem onde Jesus chora, pois, de certa forma, tal fato os autoriza a derramarem suas lágrimas sem serem julgados, por si mesmos ou pelos demais.

Nesse ponto, novamente refletimos sobre quão violenta é a sociedade em que vivemos, onde a divisão de gêneros e os papéis que lhe cabem deslegitimam o choro dos homens, que são levados a ocultar e a trancafiar essas emoções, até que se tornem "fortes", em outras palavras, até que escondam tão bem seus sentimentos que não pareçam mais tê-los. Sobre isso, Abimael diz o seguinte: "penso que muitos homens fingem ser fortões, porém, algum dia, na calada da noite, eles choram bem baixinho e escondidinhos para que ninguém veja suas lágrimas rolarem". Nesse sentido, Eliseu afirma "confesso que não sou chorão, mas choro sempre. E na maioria das vezes o meu choro é um choro embargado, choro pra dentro de mim mesmo. Não tenho vergonha de derramar minhas lágrimas. Chorar é humano. Junto com o choro a autenticidade de ser eu mesmo". Dessa maneira, pensamos que essas são ações de uma força enorme, pois quando os homens reforçam sua capacidade de amar e de serem amados ou de chorarem e não se envergonharem disso, estremecem as grades que aprisionam e trancafiam suas capacidades de ser, sentir e existir.

A escrita literária traz a possibilidade de as pessoas (re)criarem suas histórias e experiências, atribuindo novos sentidos e significados. Em vista disso, tivemos histórias como a de "Marcos", de autoria de Abimael. Nesse relato, o protagonista caía num choro sentido sempre que abraçava a mulher amada, era um choro sem explicação, que surgia estando ele

Revista Extensão \& Cidadania, v. 9, n. 16, p. 212-231, jul./dez. 2021. 
feliz ou triste. Segundo o narrador do relato escrito por Abimael, "uma vez ele [Marcos] me disse que o amor que sentia por ela era um tal de amor platônico; uma coisa de espírito para espírito". Já no escrito de José Valdir, o narrador conta a história de um homem que desde criança era apaixonado por música, tanto que um dia venceu um concurso musical. O prêmio era um contrato com uma gravadora. Chegando lá, no entanto, o homem precisou ouvir que, apesar de ter uma voz boa, suas composições eram ruins, de forma que não iriam gravar música nenhuma. Saindo dali o homem chorou bastante, contudo, "foi aí que resolveu erguer a cabeça e encarar a vida como ela é, feita de momentos de alegrias, tristezas, conquistas e perdas, e de lágrimas geradas por tantas emoções, afinal nessa vida quem não chora?”.

Por último, num formato distinto dos outros, recebemos o poema Lágrimas, de João Carlos, que transcrevemos a continuação:

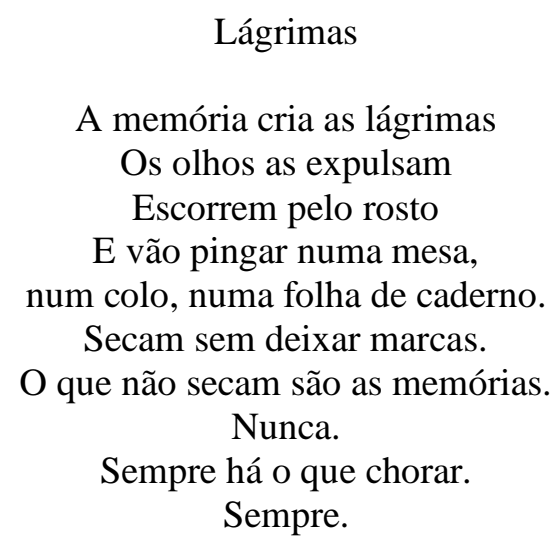

(... Noite. Palavras em fuga. Eu as recolho e monto um desabafo, antes que as esqueça e o travesseiro as absorva. Como faz com as minhas lágrimas, quase secas, de tão imaginárias). (José Carlos)

Tais textos, mobilizados pelo rap Jesus Chorou, que por sua vez se inspira em um texto bíblico, permite-nos explorar com bastante evidência as diferenças importantes que enxergamos entre o trabalho com literatura e o trabalho religioso em uma vertente fundamentalista, na medida em que a linguagem literária permite a ampliação de significações e a abertura de múltiplos sentidos, de um modo que não acontece quando se busca encontrar uma única verdade no texto. Isso não diz respeito apenas aos textos, mas aos modos de lê-los e de recriá-los livremente. Nesse sentido, é possível inclusive fazer uma leitura literária de um texto de matriz religiosa, uma vez que não se busque nele uma verdade definitiva, mas que se parta dele para seguir buscando, questionando e encontrando matrizes para novas histórias. A imagem de um Jesus que chora é muito preciosa para ficar reduzida a uma única leitura. Ela é especialmente

Revista Extensão \& Cidadania, v. 9, n. 16, p. 212-231, jul./dez. 2021. 
interessante para mobilizar outras histórias de homens que choram, muitas delas trancafiadas em diversas camadas de sofridas interdições.

\section{A escrita enquanto exercício de liberdade}

Em nossa primeira troca de cartas, perguntados sobre o que pensavam acerca da nossa proposta, recebemos a seguinte resposta de um deles: "Eu acho fascinante (...), pois me ajuda a "LIVRAR" o que está preso dentro de mim. (...) isso irá me libertar da prisão inconsciente." (Clésio). Outro participante explicou que gostou de um poema “(...) porque fala[va] da escrita como importante forma de expressão, da fascinante forma que têm o poder de (...) expandir, transmitir, transformar sentimentos, pensamentos e comportamentos. Com efeitos na aprendizagem para a vida". (Eliseu). O poema a que Eliseu se refere é de autoria de Donizeti dos Santos Junior, e é fruto de oficinas realizadas pelo projeto em 2018:

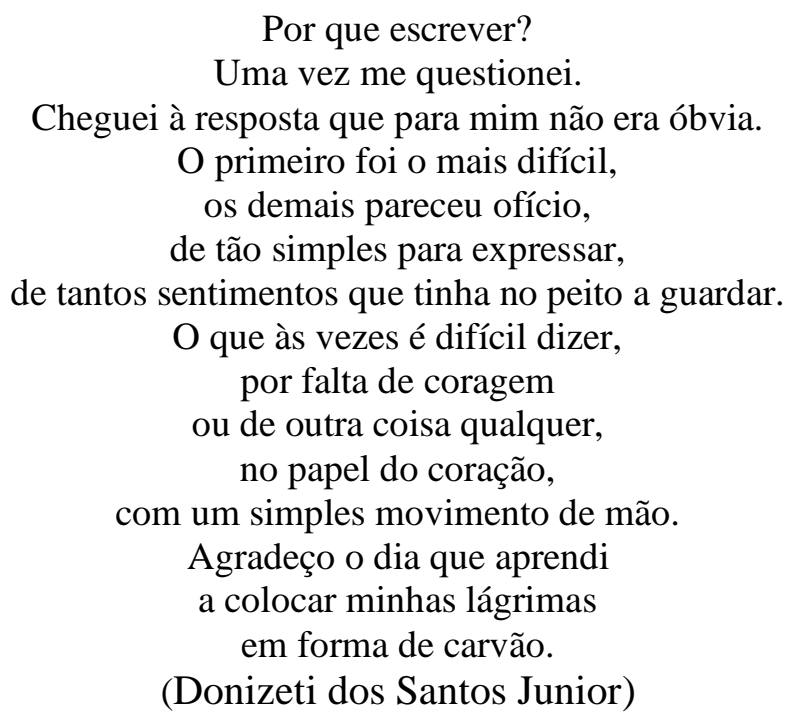

Tendo em conta os comentários de Clésio e Eliseu, gostaríamos de expor uma breve reflexão sobre a escrita enquanto exercício de liberdade tanto para nós, organizadores das oficinas do Direito à Poesia quanto para os participantes privados de liberdade. Para ficar com um exemplo conhecido: naquele poema de Vinicius de Moraes, Operário em construção, há uma tomada de consciência por parte do sujeito a respeito do seu próprio poder criativo: "Naquela casa vazia / Que ele mesmo levantara / Um mundo novo nascia / De que sequer suspeitava". Podemos dizer que ocorre algo semelhante quando exercitamos a escrita literária

Revista Extensão \& Cidadania, v. 9, n. 16, p. 212-231, jul./dez. 2021. 
já que vamos tomando consciência e reivindicando nosso poder de dizer e fazer. Partindo de exercícios vamos aprendendo a construir pequenas obras e a colocá-las em circulação numa comunidade de leitores críticos e abertos ao diálogo, sendo que a recepção dessas pequenas obras abre a possibilidade para que os participantes modifiquem a sua própria percepção da realidade.

Sem esgotar toda complexidade que envolve a escrita e a leitura de textos literários, sobretudo em condições adversas, gostaríamos de destacar a experiência de certo distanciamento da realidade cotidiana proporcionado pela escrita literária e que pode contribuir para pensarmos a seu respeito enquanto exercício de liberdade. Tal distanciamento apresenta ao menos um duplo aspecto: é um distanciar-se próprio na memória e na imaginação e que mobiliza paixões e pensamentos, sendo que é nesse mobilizar afetivo que parece se dar certa experiência de libertar-se de... Podemos dizer que a literatura está vinculada aqui a um processo de reflexão que ilumina aspectos da vida de cada um de nós e da nossa história (que não é nunca puramente individual), assim como à possibilidade de narrar e continuar essa história de outras formas. Conforme afirma a antropóloga Michèle Petit (2009, p.15), uma das referências teóricas que inspirou nosso projeto “(...) o que a leitura também torna possível é uma narrativa: ler permite iniciar uma atividade de narração e que se estabeleçam vínculos entre os fragmentos de uma história, entre os que participam de um grupo e, às vezes, entre universos culturais".

A arte e a literatura modernas são indissociáveis do conceito de liberdade - liberdade de falar, criar, construir, estabelecer diálogo, alterar a ordem das coisas. Daí que ambas possam ser consideradas espaços privilegiados de desassujeitamento. Em termos do universo prisional, poderiam ser definidas como espécies de alvarás ficcionais de soltura. Contudo, é preciso reconhecer, como já foi observado anteriormente, que essa liberdade da literatura e da arte sempre teve mecanismo de regulação como, por exemplo, por meio de especialistas que determinam o que conta como artístico e quem pode ser reconhecido como escritor. Além disso, representações literárias e artísticas podem ter contribuído à expansão do sistema de controle e vigilância, como nos casos das obras que ajudaram a consolidar a figura do delinquente. Nesse sentido, se a literatura pode ajudar a processos de libertação no cárcere, trabalhos de literatura no cárcere como o que propomos também podem ser uma forma de libertar a literatura de suas amarras institucionais e recuperar o que têm de mais transgressor, tirando-a da mão dos especialistas e abrindo-a para outros usos.

Revista Extensão \& Cidadania, v. 9, n. 16, p. 212-231, jul./dez. 2021. 
Para o Direito à poesia, trabalhar com literatura em prisões se vincula com o desejo de tirar as coisas do lugar que ocupam dentro de uma ordem social que reconhecemos como extremamente desigual. Por isso, consideramos a reflexão artística e literária simultaneamente como estética, ética e política. Trabalhar com literatura em prisões significa tentar pensar e começar a produzir outras formas de distribuição dos espaços, assim como em outras formas de circulação, tal como sugerido por Jacques Rancière: uma re-divisão do sensível que se apresenta quando conseguimos transgredir, ainda que provisoriamente, os espaços reais ou simbólicos de exclusão, em que certos corpos e certas vozes eram invisíveis, inaudíveis, ou não autorizados a circular. Essa transgressão dos espaços de poder permite vislumbrar a potencial emergência de uma comunidade democrática, onde todos são reconhecidos em sua posição de sujeitos. A ordem policial cede lugar à política e a uma nova política da escrita (RANCIÈRE, 2009, 2017).

Trabalhar com literatura em prisões significa também desrespeitar os muros existentes, na procura de uma vida mais livre e segura, ou seja, daquilo que a existência da prisão promete resguardar, mas fracassando programaticamente desde sempre (FOUCAULT, 1987). Como disse Angela Davis (2018, p. 16-17), a prisão, na verdade, serve para nos livrar "da responsabilidade de nos envolver seriamente com os problemas de nossa sociedade, especialmente com aqueles produzidos pelo racismo e, cada vez mais, pelo capitalismo global".

A pandemia de coronavírus escancarou uma vez mais a extrema vulnerabilidade enfrentada pelas pessoas privadas de liberdade, assim como a insegurança que isso implica não só para essas pessoas, mas também para o restante da população.

\section{O cárcere em tempos de pandemia}

A nova e intempestiva realidade surgida a partir da percepção de que a Covid-19 era uma pandemia mundial, gerou dinâmicas desconhecidas de ser e estar para muitas pessoas até então. O confinamento obrigatório mobilizou vários questionamentos, a partir dos quais tem sido possível evidenciar as diferenças tão absurdamente grandes que se vivem na sociedade, como, por exemplo, quem pode cumprir realmente o confinamento? É possível não passar necessidades perante tal confinamento? $\mathrm{O}$ que acontece com as pessoas que já se encontram numa situação de confinamento?

Para quem se encontra em privação de liberdade, como medida punitiva, a pandemia indiscutivelmente reforçou as outras privações de direitos que de maneira irregular embora

Revista Extensão \& Cidadania, v. 9, n. 16, p. 212-231, jul./dez. 2021. 
sistemática já aconteciam. Neste tempo, no qual aparecem com mais força as necessidades psicoafetivas, a proibição das visitas de familiares nos cárceres, limitou a troca de afetos e a entrada de produtos básicos de subsistência que as famílias acabam provendo, gerando uma precarização ainda maior das condições no interior das prisões. Como é conhecido, o Estado em quase nenhum caso se encarrega de fornecer adequadamente tudo o que as pessoas privadas de liberdade precisam para ter condições dignas de vida. Muito pelo contrário, a respeito é expressiva a seguinte declaração recolhida no Relatório da Pastoral Carcerária do ano de 2020: "Estão deixando os presos com suspeita junto com os outros, e já ouvi falar que é 'pra deixar morrer'. Estão todos sem água pra beber, tomar banho ou lavar [as] mãos (...)" (PASTORAL CARCERÁRIA, 2021) ${ }^{2}$.

O isolamento decorrente da pandemia provocou em muitos de nós sentimentos de desesperança, de solidão, de ansiedade, de tristeza, o que de alguma maneira nos dá uma ideia do que significa a privação de liberdade. Porém, de certa forma essa situação inédita nos fez parar para pensar um pouco mais sobre nossas práticas cotidianas ou em formas de nos (re)inventarmos em tempos pandêmicos. Todo o processo de troca de cartas e os exercícios de escrita propostos, acabou por nos fazer refletir sobre o que estamos criando em isolamento social, sobre a importância de trabalharmos mais a nossa imaginação, nossa interação entre nós, com os recursos possíveis, e nossa atenção em relação à lógica que nos empurra ao produtivismo, mesmo em tempos tão excepcionais como o que estamos vivendo.

Tais reflexões acabaram entrando em consonância com a leitura do artigo "O que aprendemos sobre isolamento com artistas da prisão" de Janie Paul (2020), professora de arte e design da Universidade de Michigan, Estados Unidos. Esse texto fala sobre o processo de criação dos artistas da prisão de Michigan e de como cada pessoa se encontra no campo da arte, descobrindo dentro do cárcere maneiras de se expressar pela pintura, pela escrita, por esculturas, a partir de um trabalho intenso de observação, de imaginação e de experimentação de diferentes materiais, a partir da relação peculiar com o tempo e com o espaço que se vive sob a condição de privação de liberdade. Anualmente, seus trabalhos são apresentados em exposições organizadas por Janie, as quais revertem em remuneração aos artistas, mediante a venda de suas obras.

Muitas pessoas ignoram o fato de que no cárcere também se produz arte, às vezes parece ser difícil de imaginá-lo, tanto pela dureza do lugar quanto pelos preconceitos que fazem pensar que na prisão as pessoas seriam incapazes de criar algo de bom. Logo, é muito importante dar

Revista Extensão \& Cidadania, v. 9, n. 16, p. 212-231, jul./dez. 2021. 
visibilidade às possibilidades e habilidades que pessoas em privação de liberdade tem de criar com os poucos materiais que lhe são dispostos.

O referido artigo sobre os artistas da prisão de Michigan foi compartilhado em uma de nossas cartas. Surgiram múltiplos comentários a partir da leitura e interpretação do texto, muitos deles mostrando a identificação que os participantes das oficinas sentiram ao se verem como artistas da prisão, a partir da arte do crochê. O crochê é uma das práticas amplamente difundidas entre os privados de liberdade, ensinada espontaneamente entre eles, que compartilham esse aprendizado entre si de galeria em galeria, de cela em cela, criando a partir dessa técnica tapetes, redes de dormir, bonés e afins.

Trata-se de um conhecimento que favorece a autonomia e a fraternidade entre as pessoas, ajudando-as a sentirem-se pertencentes a um lugar nesse fazer, tecendo sonhos e afetos nas descobertas do famoso crochê. São em atividades como essas que os artistas da prisão buscam neste processo formas de distrair a mente, praticando a paciência e a persistência em cada ponto. Com agulhas e barbantes descobrem um novo hobby ou até mesmo uma profissão para se levarem nos novos caminhos a serem traçados.

\section{Conclusão}

Desde o começo da troca de cartas, propusemos que. ao finalizar o ano, a experiência fosse recolhida em uma antologia dos textos trocados e escritos a partir da oficina epistolar. A ideia inicial era lançar no final do ano um livro feito de papelão, como fizemos em outras edições da oficina. Contudo, ao chegar no final do ano, decidimos optar por um modelo de edição em papelão como proposto pelo escritor e editor argentino Carlos Ríos, que tem uma longa experiência dando oficinas de literatura em presídios de seu país. Uma das propostas da Oficina perambulante, a editora de Rios, é a edição de antologias de fanzines em caixas recicladas de sucos, leites e achocolatados. O escritor transforma as caixas em pequenas bibliotecas de fanzines, além de caixas de ferramentas variadas. A ideia é que a pessoa que receba a caixinha, pensada para circular facilmente entre celas, pegue dela e acrescente nela o que quiser.

Seguindo o modelo proposto por Ríos, optamos por criar pequenas bibliotecas perambulantes, utilizando caixinhas de leite em que colocamos fanzines com alguns dos textos que consideramos mais significativos das nossas trocas de cartas (Figura 1).

Revista Extensão \& Cidadania, v. 9, n. 16, p. 212-231, jul./dez. 2021. 
Figura 1 - Caixa de fanzines

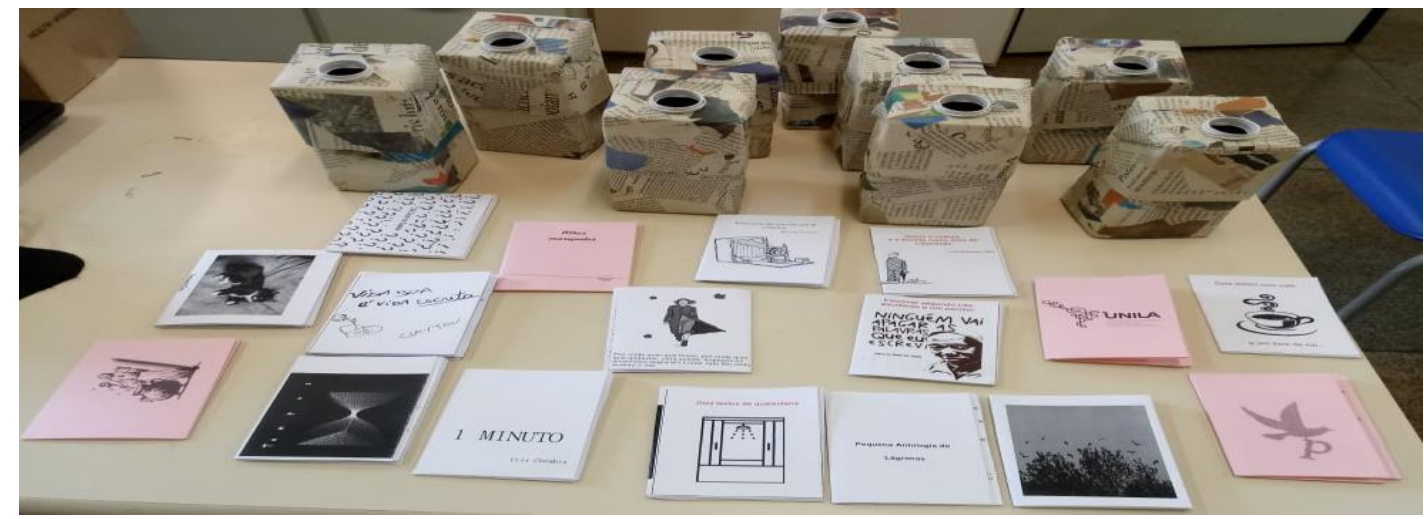

Fonte: Maria Luiza da Silva, 2020.

Nosso desejo era ter escolhido os textos e montar as caixinhas junto aos participantes das oficinas, mas isso não foi possível devido às dificuldades de acesso à penitenciária e ao pouco tempo com que contávamos para a atividade no final do ano. Com a expressa autorização dos participantes das oficinas para publicar seus textos, nós fizemos a seleção de matérias e elaboramos as pequenas bibliotecas, uma para cada um dos participantes. As caixinhas são um registro das trocas que mantivemos com as pessoas privadas de liberdade durante o período de confinamento. Textos de Gloria Anzaldúa, Ricardo Piglia, Clarice Lispector e Carolina Maria de Jesus aparecem do lado de escritos dos participantes privados de liberdade e nossos, os organizadores das oficinas. A caixinha convida o leitor a passar de um fanzine a outro, a pôr em diálogo e confronto as vozes diversas. Por isso, consideramos que a caixinha materializa de forma bastante adequada a proposta de nosso projeto.

O objetivo principal do Direito à poesia é esse: perfurar muros para liberar falas, criar as condições para que nós e as pessoas privadas de liberdade possamos falar da forma mais livre possível. Isto quer dizer também criar condições para que fale uma voz própria, entendida como uma voz que exprima a singularidade da própria vida. Trata-se de procurar uma voz singular, mas não individual nem individualista.

Por fim e para concluir, ainda que a realização da Oficina Epistolar tenha implicado em uma mudança bastante profunda em relação à dinâmica dos encontros presenciais, as cartas foram o veículo para fazer entrar e sair falas da prisão. De fato, o primeiro passo nessa procura é criar um espaço de escuta, uma comunidade de acolhimento de vozes diversas, que faça os e as participantes sentirem-se livres para falar. É preciso poder falar livremente, mas sem renunciar à responsabilidade de manter essa comunidade de acolhimento de vozes divergentes.

Revista Extensão \& Cidadania, v. 9, n. 16, p. 212-231, jul./dez. 2021. 
Figura 2 - Fragmentos de zines

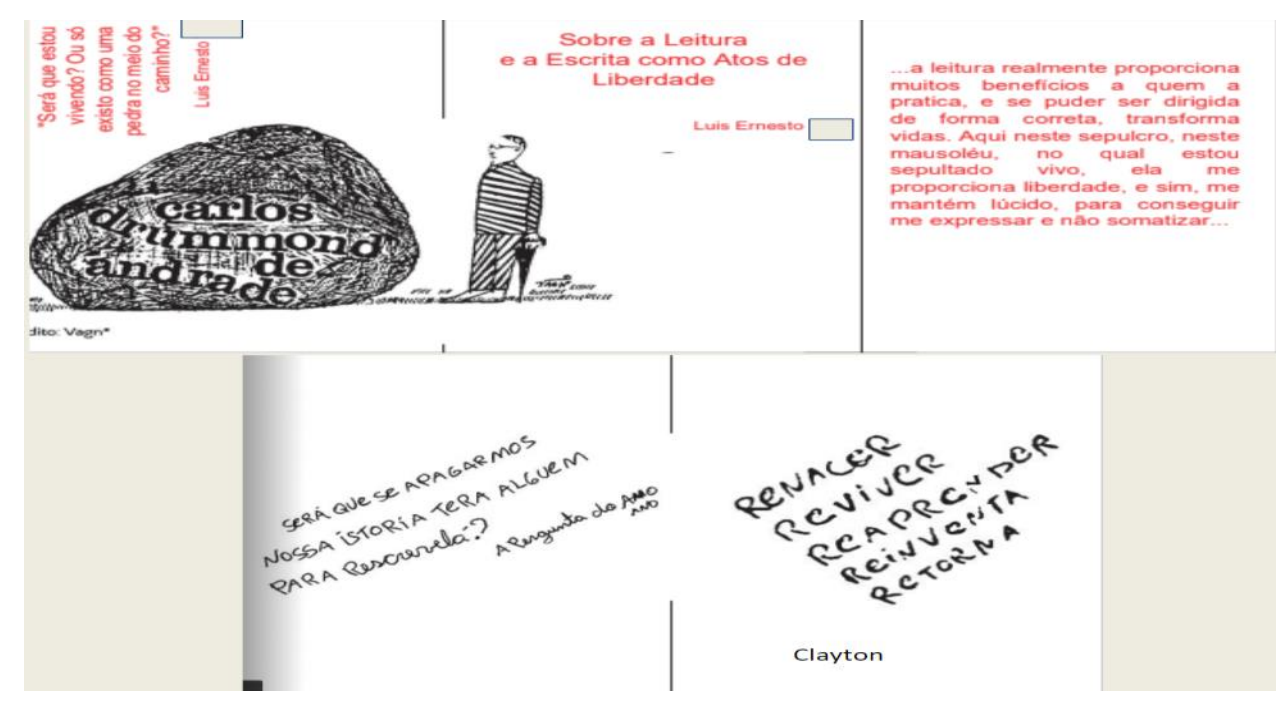

Fonte: arquivo pessoal, 2020.

\section{Notas}

1. Alguns dos projetos podem ser conhecidos no canal de vídeos de apresentação das/os participantes do evento no link: https://www.youtube.com/channel/UCfBR8AUVlNi4ipVuAxpwC5w/videos

2. Vale dizer que, cientes dos riscos que a pandemia trouxe para uma população já extremamente vulnerável como a privada de liberdade, além de para as pessoas que trabalham em presídios e, por extensão, para toda a população, Direito a poesia aderiu à Rede Feminista Anticarcelária Latinoamericana. Esta rede, composta por organizações e coletivas do Brasil, da Argentina, do Equador, do Chile e do México, está promovendo uma campanha pela libertação imediata de mulheres presas na região. Os materiais da campanha podem ser acessados no site: https://feministasanticarcelarias.org/

\section{Referências}

AGAMBEN, Giorgio. O que é o contemporâneo? E outros ensaios. Trad. Vinicius Nicastro Honesco. Chapecó: Argos, 2009.

BAJOUR, Cecília. Ouvir nas entrelinhas: o valor da escuta nas práticas de leitura. Trad. Alexandre Morales. São Paulo: Pulo do Gato, 2012.

BRASIL. Departamento Penitenciário Nacional. Levantamento Nacional de Informações Penitenciárias: Período de julho a dezembro de 2019. 2019. Disponível em: https://app.powerbi.com/view?r=eyJrIjoiYWY5NjFmZjctOTJmNi00MmY3LThlMTEtNWY wOTImODFjYWQ5IiwidCI6ImViMDkwNDIwLTQ0NGMtNDNmNy05MWYyLTRiOGRh NmJmZThlMSJ9. Acesso em: 1 set. 2021.

DAVIS, Angela. Estarão as prisões obsoletas? Trad. Marina Vargas. Rio de Janeiro: Difel, 2018.

Revista Extensão \& Cidadania, v. 9, n. 16, p. 212-231, jul./dez. 2021. 
DERRIDA, Jacques. Paixões. Trad. Loris Z. Machado. Campinas: Papirus, 1995.

DERRIDA, Jacques; ROUDINESCO, Elisabeth. De que amanhã... diálogo. Trad. André Telles. Rio de Janeiro: Jorge Zahar Editor, 2004.

FOUCAULT, Michel. Vigiar e punir: nascimento da prisão. Trad. Raquel Ramalhete. Petrópolis: Vozes, 1987.

GOFFMAN, Erving. Manicômios, prisões e conventos. São Paulo: Perspectiva, 1974.

NIETZSCHE, Friedrich. Segunda consideração intempestiva: da utilidade e desvantagem da história para a vida. Trad. Marco Antônio Casanova. Rio de Janeiro: Relume Dumará, 2003.

PASTORAL CARCERÁRIA. Relatório 2020 - A Pandemia da Tortura no cárcere.

Disponível em: https://carceraria.org.br/wp-

content/uploads/2021/01/Relatorio_2020_web.pdf. Acesso em: 28 jan. 2021.

PAUL, Janie. O que aprendemos sobre isolamento com artistas da prisão. Nexo, 12 jun. 2020. Disponível em: https://www.nexojornal.com.br/externo/2020/06/12/O-que-aprendemos-sobreisolamento-com-artistas-da-prisão. Acesso em: 22 set. 2021.

PÈTIT, Michele. A arte de ler ou como resistir à adversidade. Trad. Arthur Bueno e Camila Boldrin. São Paulo: Ed. 34, 2009.

RANCIÈRE, Jacques. Da partilha do sensível e das relações que estabelece entre política e estética. In: RANCIÈRE, Jacques. A partilha do sensível - estética e política. Trad. Mônica Costa Netto. São Paulo: Ed. 34, 2009. p. 15-26.

RANCIÈRE, Jacques. Políticas da escrita. Trad. Raquel Ramalhete, Laís Eleonora Vilanova, Lígia Vassalo e Eloísa Araújo Ribeiro. São Paulo: Ed. 34, 2017.

RODRÍGUEZ TORRES, Mario René; CHECCHIA, Cristiane. Direito à poesía: creando aberturas en la universidad, la cárcel y la literatura. Athenea Digital, v. 20, n. 3, 2020. e2674. Disponível em: https://doi.org/10.5565/rev/athenea.2674. Acesso em: 39 set. 2021

Recebido: 13.10 .2021

Aceito: 29.11.2021

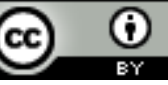

This work is licensed under a Creative Commons Attribution 4.0 International License.

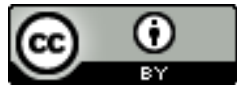

Este trabalho está licenciado com uma Licença Creative Commons - Atribuição 4.0

Internacional.

Revista Extensão \& Cidadania, v. 9, n. 16, p. 212-231, jul./dez. 2021. 